\title{
Public Perception and Perceived Landscape Function of Urban Park Trees in Tabriz, Iran
}

\author{
Ahmad Hami ${ }_{1}$, Sreetheran Maruthaveeran ${ }_{2}^{*}$ \\ 1 Department of Landscape Engineering, Faculty of Agriculture, University of TABRIZ, 29 Bahman, 5166616471 Tabriz, Iran \\ 2 Department of Landscape Architecture, Faculty of Design \& Architecture, Universiti Putra Malaysia, 43400 Serdang, Selangor \\ Darul Ehsan, Malaysia
}

\begin{abstract}
Landscapes of parks may contribute an important function in the urban park with a wide range of benefits. However, there is a lack of understanding of the publics' preferences for parks' landscape funtions and benefits in middle-east countries such as Iran. About 275 park users were interviewed using photo-questionnaire in Tabriz, Iran using five point Likert scale ( $1=$ strongly disagree,.. $5=$ strongly agree) for measuring their preference level. Descriptive analysis, factor analysis, and variance analysis (Independent sample t-test and ANOVA) were used for analyzing the data. The results revealed the majority of the participants were male (54.5\%), single (65.09\%), highly educated (71.4\%), below 40 years old (62.9\%), and visit the park with family members $(43.3 \%)$ in the evenings (54.5\%). The participants preferred the presence of Salix alba followed by Pinus nigra, Platanus occidentalis, and Morus alba in the urban park, respectively. "Flowering purpose" (mean $=4.21)$ and "green enlargement" (mean= 4.20) were important functional dimensions, whilst, "health care" (mean= 4.33) and "mental recovery" (mean= 4.29) landscape benefits in urban parks. It is concluded that, perhaps, attributions of trees such as creating shade, with the canopy on top, and having large leaves are significant factors on publics' landscape preferences.
\end{abstract}

\section{Keywords:}

Landscape Function, Landscape Assessment, Landscape Benefits, Photo-questionnaire Design, Urban Forestry

\footnotetext{
*Corresponding author. Email: sreetheran@upm.edu.my

(C) The Authors. 2018. Landscape Online. This is an Open Access article distributed under the terms of the Creative Commons Attribution License (http://creativecommons.org/licenses/by/4.0), which permits unrestricted use, distribution, and reproduction in any medium, provided the original work is properly cited.
} 


\section{Introduction}

\subsection{Motivation}

Landscape in residential areas provides numerous benefits and functions such as environment, social, aesthetic and economic benefits. Rapid urbanizations have dramatically limited human contact with natural elements in residential areas. Urban public green spaces such as urban parks are a venue to see green elements. Trees are integral elements of urban parks in cities. They provide a huge number of benefits in parks setting and urban environment, they support healthy communities by producing fresh air and offering environmental and social benefits. However, people might have different priorities towards the function of the landscape such as trees in urban parks, therefore, understanding their perception and knowledge for trees in urban parks can be helpful in designing sustainable landscape in parks. Nowadays, urban parks are considered as important public green areas to find compensation to the urban environment, thus more attention is paid to build new parks in crowded cities such as in Tabriz, Iran. Also, this study is important because participation of the public in designing landscapes for urban parks help in dealing with undesirable activities (Hami, 2014a). The finding of this study will contribute to creating the public desired landscape in urban parks in terms of function and benefits.

\subsection{History of Urban Park in Iran}

The history of public space in Iran can be traced from the time of the Persian Empire around 500 years B.C.. Majnonian (1996) stated that public spaces were used for different purposes such as a place for national ceremonies, announcing important news, crowning ceremonies, etc.. During the 14th century A.D., public spaces such as 'Chahar Bagh' were the most important part of a city. During this time, public spaces were used as a venue for social communication, national and religious ceremonies. In addition, Persian gardens were also introduced as a place to experience nature.
In the early 20th century A.D., Persian gardens became public urban parks for peoples' recreation and socialization in most of the big cities in Iran including Tabriz (Romianfar, 2008). In addition, public spaces in Iran can be considered as multipurpose areas (Hami, 2009). Urban parks were not so common in the Iranian cities due to the inadequate amount of water resources, therefore, most of the available green space in the traditional cities was a garden, which was usually built on a private land (Rismanchian, 2009). With the rapid and modern urbanization of Iranian cities, urban parks were popular choices for having access to green space. According to a previous study, peoples' preferred activities in urban parks are mostly passive entertainment and individual active activities such as walking (Hami, 2009), even though, some parks provide sports facilities such as volleyball and tennis court for the visitors. Overall, it seems urban parks in Iran are a venue for nature appreciation (Hami, 2009; Rostami, 2015) and social interaction such as for family gatherings (Hami et al., 2011). Thus, public demands and needs should be taken into consideration in the landscaping of urban parks.

\subsection{Goal of the Study}

Urban parks are usually planned according to the experts' knowledge and ideas, however, public opinion may differ from experts. On the other hand, preference studies is a practical and a systematic approach that can be used in measuring peoples' preference regarding landscape. Preference is defined as an individual's degree of like or dislike for the visual appearance of a place as compared to another (Daniel, 2001). Visual preference is an aesthetic response to a fundamental concept of human evaluation of landscape (Zube et. al., 1982). This study aims to discover public knowledge in understanding of landscape elements particulalrly the function of trees in urban parks in Tabriz. In this regard, questions for the research are as below:

1. How much do the visitors prefer landscape function dimensions in urban parks?

2. What is the visitors' preferences for different trees usage in urban parks in Tabriz? 
3. Are there significant differences between the participants' demographic factors for the dimensions of landscape function and benefit?

\section{Literature Review}

This part of the article explains theoretical base, methodology, and related studies. The study is formed based on perception and preferences of public park users.

\subsection{Expert and Public Assessment of Landscape}

Peoples' perception is the main factor in the assessment and planning of landscape (LópezMartínez, 2017). Also, a landscape is an area, as perceived by people, whose personality and character is the result of actions and reactions of natural and human factors (Council of Europe, 2000). The differences between attitudes of experts and non-experts have already been proved in some research (Dupont et al., 2015; Muratet et al., 2015). Muratet et al (2015) investigated the difference between a botanist and park user's perceptions about the richness of plants in a park and the results showed that park users mainly recognized the cultivated plants promoted by gardeners, whereas the botanist more frequently observed wild plants. Furthermore, the plant richness estimation by park users was much lower than the botanist's count. Dupont et al (2015) reported that experts have explored landscape images in a wider and more comprehensive way and they interpret landscape more easily. So these studies concluded that there is a significant difference in viewing patterns between landscape experts and non-experts. It seems that some other factors such as landscape function and benefits might affect non-experts' preferences into plants' usage in urban parks, whereas experts mostly consider plants' physiology demands such as water etc..

\subsection{Socio-demographic Variables}

Perception and preference of landscape are also influenced by socio-demographic, economic, sociological, physical, and psychological character- istics of the people (Tveit, 2009). Many researchers have shown that socio-demographic and socioculture factors influence landscape preference studies (Hami \& Tarashkar, 2018; López-Martínez, 2017). Other researchers have also proved the effect of age and education (Wang \& Zhao, 2017), gender (Hami et al., 2016), and house types (Sullivan, 1994) in preference and perception studies. One study stated the importance of income level in peoples' preferences (Ferreira \& Moro, 2013). Investigation on the impact of these variables in this study may cause urban planners and landscape designers to consider users' characteristics in the creation of new projects.

\subsection{Landscape Benefits and Function}

Lohr and Pearson-Mims (2002) found that urban residents generally held very positive attitudes toward trees in cities and that these attitudes were even more positive if they had participated in activities involving gardening and nature during childhood. Greenery provides multiple social benefits in urban environments; it improves contact between communities of residents, motivates for physical activity, mitigates stress and enhances social cohesion as mentioned by Van Dillen et al. (2012). In this study, also most of the respondents agreed on that trees are calming. Chen et al., (2009) found that aesthetical benefits of trees are important but urban green also provides recreation facilities for dwellers and maintenance of social activities (Kazmierczak, 2013). Nilsson and his colleagues concluded that trees have great contribution in urban aesthetic quality, human mental and physical health, and environmental quality (Nilsson et al., 2011). Maas et al. (2009) claimed that people, who live in greener environments have a lower rate of specific diseases such as depression, and anxiety disorder compared to those who live in less green environments. A tree also improves urban visual quality and aesthetic value, induces the sense of spiritual well-being, and has many ecological benefits including improved air quality, and mitigating the urban heat island effect (Keniger et al., 2013). A study disclosed that urban biodiversity correlates positively with a human's well-being in a rapid urbanized world (Botzat et al., 2016). 
Review of the literature showed the importance of understanding public approaches to landscape management processes because new developments will ultimately be experienced by people (Vouligny et al., 2009). Overall, landscaping of a park is merely not plant selection with the ecological perspective, but human feelings and satisfaction should be considered as well. The below section describes how the public preference and perception for park landscapes will be assessed.

\section{Methodology}

\subsection{Study Area}

This research was conducted in Tabriz, Iran, which is the capital of East Azerbaijan and is located at the extreme north-west of Iran $\left(46^{\circ} 17.514^{\prime}\right.$ E $38^{\circ} 4.8^{\prime}$ N) $4580 \mathrm{ft}$. above sea level with an area of about 131 square kilometers (Rahimi, 2006). Based on the results of the census of 2016, the population of the city is $1,558,693$ people and thus, it is the fifth highest populated city of Iran (Hami \& Tarashkar, 2018). In the winter, the average temperature is $12.4^{\circ} \mathrm{C}\left(88.4^{\circ} \mathrm{F}\right)$ and in the summer the average temperature is $34.1^{\circ} \mathrm{C}\left(110.1^{\circ} \mathrm{F}\right)$. Lack of water resources is the most important climatic problem in the city; meanwhile, the annual rainfall is only about $321 \mathrm{~mm}$ and most of the rain occur during winter and spring. In total, green space area in Tabriz is about $4.7 \mathrm{~m}^{2}$ per capita (in 2006) and this amount was less than the proposed per capita $\left(7-12 \mathrm{~m}^{2}\right)$ by the Ministry of Housing and Urban Development (Ghorbani, 2006). In 2011, the green space capita in Tabriz has reached $12 \mathrm{~m}^{2}$ which is exactly the ministry's requirement.

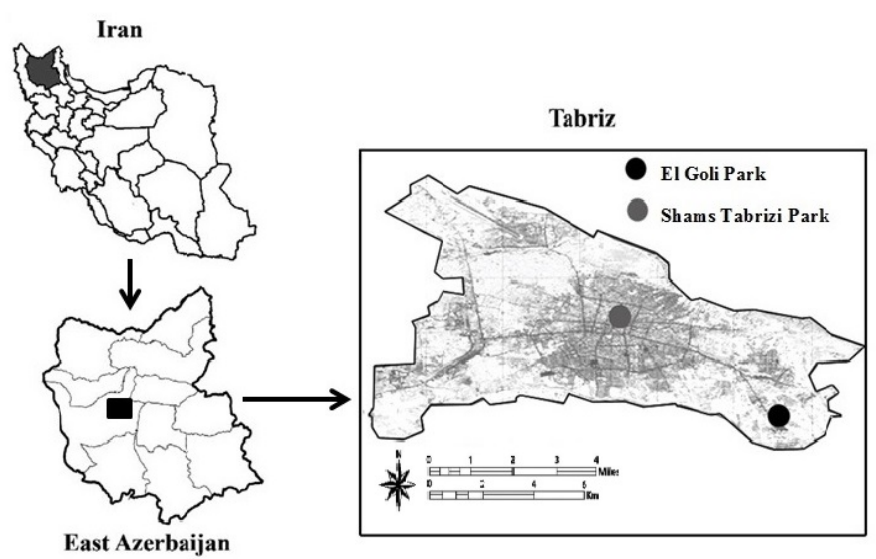

Figure 1: Map of the Study Area

However, based on "Tabriz view in 2018", the green space per capita should be increased to $25 \mathrm{~m}^{2}$ per capita. Even though the commitment is applicable, Tabriz like other city in Iran is facing a lack of rain and snow so development of green areas need very high investment.

\subsection{Plant Distributions in Urban Parks in Tabriz}

As the photos depict in below, an appropriate planting patterns have not been used for plantation of trees in urban parks in Tabriz (Fig 2). Also, the parks lack enough facilities for public usage.
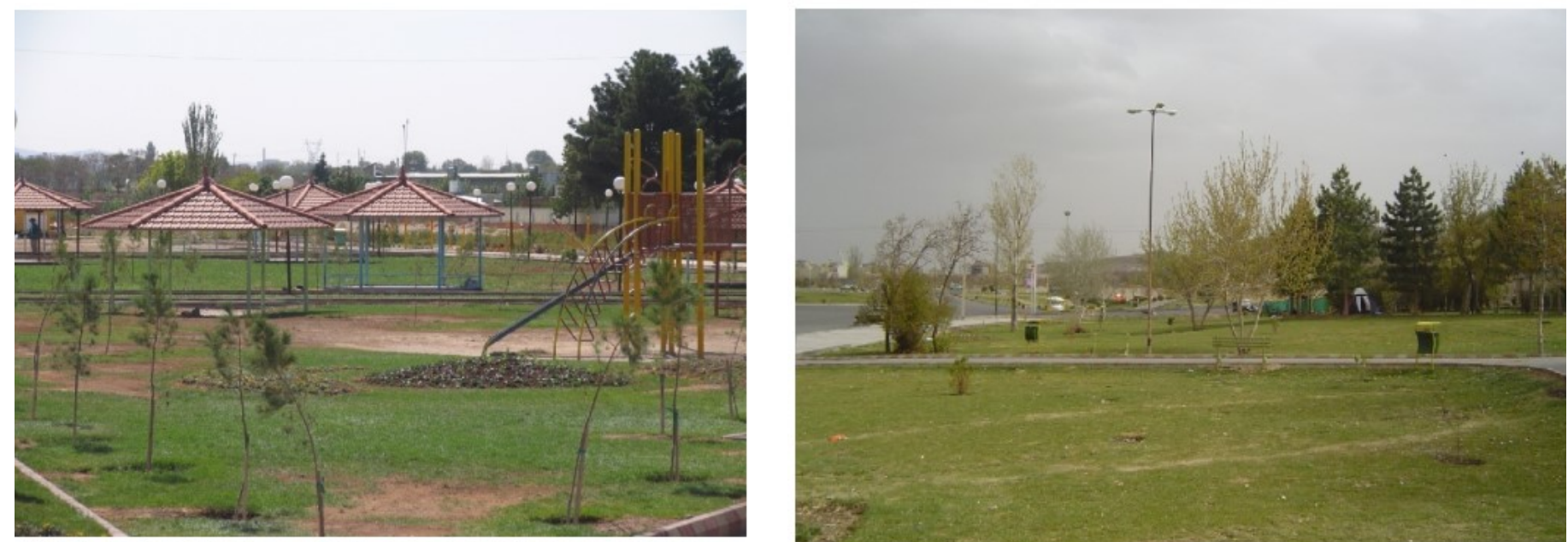

Figure 2: Pictures of Urban Parks in Tabriz, Iran 
Because the city of Tabriz experiences cold and dry seasons, the diversity of plants is very limited. The most important source of its vegetation belongs to Arasbaran forests, which can be found in the northeast of Azerbaijan. There are also some other exotic plants that have been cultivated in this region for many years. The most popular species in these public spaces can be divided into evergreen trees such as Cupressus arizonica, Cupressus orientalis, Juniperus communis, Pinus nigra, Tamarix pentandra, Thuja occidentalis, and deciduous trees which includes Acer negundo, Eleagnos angustifolia, Fraxinus excelsior, Gleditsia triacanthos, Morus alba, Morus nigra, Platanus occidentalis, Populus alba, Populus nigra, Robinia pseudoacacia, Salix alba, Salix nigra, Ulmus nigra, etc..

\subsection{Questionnaire Structure}

The development of the survey instrument began with reviewing of landscape function and benefits items followed by an informal observation in the park. The informal observation was conducted to record the activities going on in the park to complete proposed activities. The survey was pilot tested by 30 individuals including students and the nonexperts to make sure that the reliability of the items is acceptable.

\subsubsection{Socio-demographic Variables}

The first part of the questionnaire consisted of categorical questions including park visitation patterns, the company for park visiting, frequency of visiting time, and season for going to the park. There were four basic categorical questions of respondents ${ }^{\prime}$ demographic information consisting of gender, age, marital status, and education level. Age was divided into 6 categories; 18-29, 30-39, 40-49, 80-59, and > 60 years. Education level included 4 options; High school, diploma, Bachelor, Master and above.

\subsubsection{Landscape Functions}

The participants' preferences ere also examined about function of landscape elements such as trees and flowers in the park. The statements referring to their opinion for eleven functional options include: sitting in the shade of trees, being close to scented flowers, perception of designed and non-designed green space in park, the use of fruit plants, etc.. The Likert scale is the most used measurement technique to assess peoples' opinion for landscape benefits. The function alternatives were presented to the participants using a 5 point Likert scale $(1=$ strongly disagree, 2 = disagree, $3=$ neither agree nor disagree, 4 = agree, 5 = strongly agree).

\subsubsection{Landscape Benefits}

The focus of this section is to understand the benefits and outcomes that landscape have for people in the aspects of ecological, physical, and health. By understanding these outcomes and benefits, designers can then integrate them in contemporary landscape designs in urban parks to create multifunctional green structures and forms. In relation to the benefits of plants, eight items about them were included in the questionnaire. The Likert scale is the most used measurement technique to assess peoples' opinion for landscape benefits. Therefore, the items were presented to the participant using a 5 point Likert scale.

\subsubsection{Preferred Activities}

Activities related to green spaces include 13 alternatives that visitors entertain in urban parks. These activities can be grouped into passive activities, nature appreciation activities, and active activities. The literature review showed that activity items were measured by using a Likert scale technique, thus, in the current study, 13 activity alternatives were presented and measured by applying a 5 point Likert scale.

\subsection{Research Population and Sample Size}

The study population consisted of park users residing in Tabriz. The population was limited to people above 18 years old because children and teenagers have different demands for coming to parks (Suhardi, 2002). In addition, their opinions and preferences may also be different for visiting parks. Children were also presumed to be under their parents' supervision and, therefore, parental permissions would have been rendered necessary. 
One of the critical issues in this research was the sampling size, because there is no exact number of park visitors in Tabriz. To solve this problem, the most relevant formula would be the formula proposed by Mitra and Lankford (1999). This formula significantly prevents error by reducing the sampling error and increasing the confidence level. According to this formula, $e=V(P(1-P) / n)$, where e is sampling error that should be less than 0.05 and $p$ is the probability that the condition exists. However, since the actual p-value is not known before the survey, the p-value is assumed to be $50 \%$ (Mitra \& Lankford, 1999). For this study, to reduce both sampling and nonsampling errors, the proposed sample size was 275 . Therefore, the sampling error based on the above formula is: sampling error $=$ Square root of $[(p)(1-p) /$ proposed sample size $] . e=V[(p) \times(1-p) / n]=V[(0.5)$ $x(0.5) / 275=3.23 \%$. The sampling error (e) indicated for this study was $\mathrm{e}=3.23 \%$, which was lower than $5 \%$; it is, thus, acceptable.

\subsection{Sampling Method}

A systematic random sampling was applied in this study. Each participant was approached every 15 minutes at a specific location close to the main entrance of the park. However, if any of the participants refused to answer the survey questionnaire, the next participant who pass by will be selected. Based on the pre-test 15-minute intervals were set, because, ten minutes was the maximum time taken for the participant to answer the survey and five minutes for the researcher to check the completed questionnaire. All the participants were briefed about the aim of the survey. The survey was administered from April 11 until May 22016 on ten weekdays between 11:00 $A M$ and 5:00 PM, and on two Fridays between 9:00 $A M$ and 5:00 PM. The survey was self-administered by the visitor at the park where the researcher was available to any assistance needed.

\subsection{Data Analysis}

In order to analyse the data, SPSS no.19 was used in this research. Descriptive analysis was conducted to interpret participants' demographic information. Mean analysis was used to rank peoples' belief about benefits and functions of trees in the park. Based on peoples' preferences, explanatory factor analysis was performed using Principal Component Analysis (PCA) to analyse the preference dimensions. In PCA or factor analysis, the principal component was used to group the items which had internal consistency between each other under one group that is known as factor. The reliability test was used to make sure that internal consistency $(\alpha)$ is close or higher than 0.7 as recommended by De Vaus (2002). In addition, independent sample t-test and one-way ANOVA were employed to analyse the differences among group means.

\section{Results}

\subsection{Participant Background Information and Park Use Patterns}

Table 1: Participants' Demographic Information and Park Use Patterns

\begin{tabular}{|l|c|c|c|}
\hline \multicolumn{2}{|l|}{ Participants } & Number & Percent \\
\hline \multicolumn{2}{|l|}{ Total public participation } & 275 & 100.0 \\
\hline Factors & Sub- category & & \\
\hline \multirow{2}{*}{ Gender } & Male & 150 & 54.5 \\
\cline { 2 - 4 } & Female & 125 & 45.5 \\
\hline \multirow{2}{*}{ Marital status } & Single & 179 & 65.09 \\
\cline { 2 - 4 } & Married & 95 & 34.54 \\
\hline & Others & 1 & 0.37 \\
\hline
\end{tabular}




\begin{tabular}{|c|c|c|c|}
\hline \multirow[t]{5}{*}{ Age(years old) } & $19-29$ & 173 & 62.9 \\
\hline & $30-39$ & 55 & 20.0 \\
\hline & $40-49$ & 30 & 10.9 \\
\hline & $50-59$ & 10 & 3.7 \\
\hline & Above 60 & 7 & 2.5 \\
\hline \multirow[t]{4}{*}{ Education } & Secondary and below & 6 & 2.2 \\
\hline & High school & 22 & 8.1 \\
\hline & Diploma & 51 & 18.1 \\
\hline & University & 196 & 71.4 \\
\hline \multirow[t]{4}{*}{ Park visitation pattern } & Friends & 83 & 30.2 \\
\hline & Couple & 38 & 14.1 \\
\hline & Alone & 35 & 12.4 \\
\hline & Family members & 119 & 43.3 \\
\hline \multirow[t]{4}{*}{ Frequency of park visitation } & Once every 6 month & 42 & 15.2 \\
\hline & Once every 3 month & 45 & 16.4 \\
\hline & Once in a month & 80 & 29.1 \\
\hline & Several times in a month & 108 & 39.3 \\
\hline \multirow{4}{*}{$\begin{array}{l}\text { Season of park } \\
\text { visitation }\end{array}$} & Spring & 88 & 32.0 \\
\hline & Summer & 158 & 57.5 \\
\hline & Autumn & 23 & 8.4 \\
\hline & Winter & 6 & 2.1 \\
\hline \multirow[t]{4}{*}{ Park visiting time } & Morning & 28 & 10.2 \\
\hline & Afternoon & 46 & 16.7 \\
\hline & Evening & 150 & 54.5 \\
\hline & Night & 51 & 18.6 \\
\hline
\end{tabular}

\subsection{Public Perception for Activities in Park Landscape}

The results show that people have the highest preferences to "sit with family under trees' shade" (mean=3.88, $\mathrm{sd}=1.17$ ) and "seeing moving water" (mean $=3.87, \mathrm{sd}=1.09$ ). Also, as shown in Table 2 , two dimensions related to preferred activities were extracted with the titles of "aesthetical pleasing" (alpha $=0.711$ ) and "relaxation and rest" (alpha $=0.699$ ). It shows that park landscape in highly preferred to engage because of aesthetical purpose than relaxation and resting aim.

Table 2: Public Preferences for Activities in Park Landscape

\begin{tabular}{|l|c|c|c|}
\hline Items & Mean & $\begin{array}{c}\text { Standard } \\
\text { deviation }\end{array}$ & Alpha \\
\hline Aesthetical pleasing & $\mathbf{3 . 7 0}$ & $\mathbf{1 . 1 2}$ & $\mathbf{0 . 7 1 1}$ \\
\cline { 1 - 3 } 1. I prefer to have good view to see moving water & 3.87 & 1.09 & \\
\cline { 1 - 3 } 2. I like designed landscape as a destiny to spending my time & 3.66 & 1.03 & \\
\cline { 1 - 3 } 3. Sitting in a place next to flower is very enjoyable & 3.52 & 1.25 & \\
\hline Relaxation and rest & $\mathbf{3 . 3 2}$ & $\mathbf{1 . 1 3}$ & \multirow{2}{*}{$\mathbf{0 . 6 9 9}$} \\
\cline { 1 - 3 } 1. I usually sit with family under trees' shade & 3.88 & 1.17 & \\
\cline { 1 - 3 } 2. I usually relax under trees without fruit & 3.60 & 1.04 & \\
\cline { 1 - 3 }
\end{tabular}




\begin{tabular}{|l|l|l|l|} 
3. I like to sit in lawn area without trees & 2.94 & 1.23 & \\
\hline 4. I prefer to sit with family under fruit trees & 2.84 & 1.08 & \\
\hline 5 I like to see mixed designed and undersigned landscape in park & 3.59 & 1.09 & \\
\hline 6 Presence of water near sitting area is not important & 2.66 & 1.25 & \\
\hline
\end{tabular}

\subsection{Public Perception of Landscape Function}

The most important function of landscape is "providing shadow in park" (mean $=4.38, \mathrm{sd}=0.94$ ) followed by "presence of water in park" (mean= 4.37, $\mathrm{sd}=0.82)$, and "like seasonal flowers in park" (mean $=4.22, \mathrm{sd}=0.87$ ). From Table 3, three dimensions for landscape function were emerged namely "presence of water" (mean $=4.31, \alpha=0.691)$, followed by "flowering purpose" (mean $=4.21, \alpha=$ 0.624 ), and "green enlargement" (mean $=4.20, \alpha=$ 0.788 ), respectively, where presence of the water is highly preferable expected function from park landscape in a park.

Table 3: Public Preferences for Landscape Function in Park

\begin{tabular}{|c|c|c|c|}
\hline Items & Mean & $\begin{array}{l}\text { Standard } \\
\text { deviation }\end{array}$ & Alpha \\
\hline Presence of water & 4.31 & 0.86 & \multirow[t]{4}{*}{0.691} \\
\hline 1. How much the presence of water is important & 4.37 & 0.82 & \\
\hline 2. How much do you like to see moving water in park & 4.33 & 0.89 & \\
\hline 3. How much is existence of fountain in park is important & 4.22 & 0.87 & \\
\hline Flowering purpose & 4.21 & 0.91 & \multirow[t]{5}{*}{0.624} \\
\hline 1. How much do you like seasonal flowers in park & 4.22 & 0.87 & \\
\hline 2. How much do you like flowering trees in park & 4.21 & 0.91 & \\
\hline 3. How much do you enjoy plants' smell & 4.10 & 1.04 & \\
\hline 4. How much do you like to touch flowers in park & 3.97 & 1.12 & \\
\hline Green enlargement & 4.20 & 0.90 & \multirow[t]{5}{*}{0.788} \\
\hline 1. How much do you like to see shadow trees in park & 4.38 & 0.94 & \\
\hline 2. How much do you like lawn area & 4.21 & 0.92 & \\
\hline $\begin{array}{l}\text { 3. How much do you agree with spreading out vertical landscape } \\
\text { in park }\end{array}$ & 4.20 & 0.85 & \\
\hline $\begin{array}{l}\text { 4. How much do you agree with expanding horizontal landscape } \\
\text { in park }\end{array}$ & 4.04 & 0.90 & \\
\hline
\end{tabular}




\subsection{Public Preference for Landscape Benefits in the Urban Park}

The results from table 4 reveal that people highly benefit from landscape by "enjoying natural scenes in park" (mean $=4.44, \mathrm{sd}=0.73$ ) and "green spaces are very good places to relax" (mean $=4.41$, sd=
0.84). Landscapes' benefit items were accumulated into two dimensions "Health care" (mean $=4.33$, alpha $=0.794)$ and "Mental recovery" (mean = 4.29 , alpha $=0.86$ ) showing people appreciate the parks' landscape to earn mental and physical health (Table 4).

Table 4: Public Preference for Landscape Benefits in the Urban Parks

\begin{tabular}{|c|c|c|c|}
\hline Items & Mean & $\begin{array}{l}\text { Standard } \\
\text { deviation }\end{array}$ & Alpha \\
\hline Health care & 4.33 & 0.85 & \multirow[t]{5}{*}{0.794} \\
\hline 1. In my opinion, green spaces are very good places to relax & 4.41 & 0.84 & \\
\hline 2. I like to spend my time in a natural environment & 4.27 & 0.82 & \\
\hline 3. Trees and green spaces create a setting for contemplation & 4.18 & 0.89 & \\
\hline 4. I want to escape from regular life for a while & 4.15 & 0.85 & \\
\hline Mental recovery & 4.29 & 0.86 & \multirow[t]{5}{*}{0.752} \\
\hline 1. I like to enjoy from natural scenes & 4.44 & 0.73 & \\
\hline 2. I like to breath in clean air & 4.38 & 0.86 & \\
\hline 3. I release mental stress and tension in green spaces & 4.37 & 0.90 & \\
\hline 4. Green spaces provide a quiet and silent setting & 4.11 & 0.97 & \\
\hline
\end{tabular}

4.5 Peoples' Perception for Trees Species in Urban Parks

Data analysis revealed that due to the highest mean score for Salix alba (mean $=3.81$, sd $=1.15$ ), to the other species such as Pinus nigra (mean $=3.80$, $\mathrm{sd}$ $=1.15)$, Platanus occidentalis (mean $=3.77, \mathrm{sd}=$ 1.06), Morus alba (mean $=3.76, \mathrm{sd}=1.04)$, and Acer negundo $($ mean $=3.67$, $s d=1.09)$, people prefer
Salix alba in urban park surrounding.

In addition, based on the mean score, three least preferred tree species in park surrounding were Ulmus nigra (mean $=3.38$, sd $=1.15)$, Elaeagnus angustifolia (mean $=3.29, \mathrm{sd}=1.27)$, and Populous alba (mean $=3.81, \mathrm{sd}=1.15)$, respectively (Figure 3 ). The result is quite surprising because people had low preferences for Ulmus nigra in park surroundings.

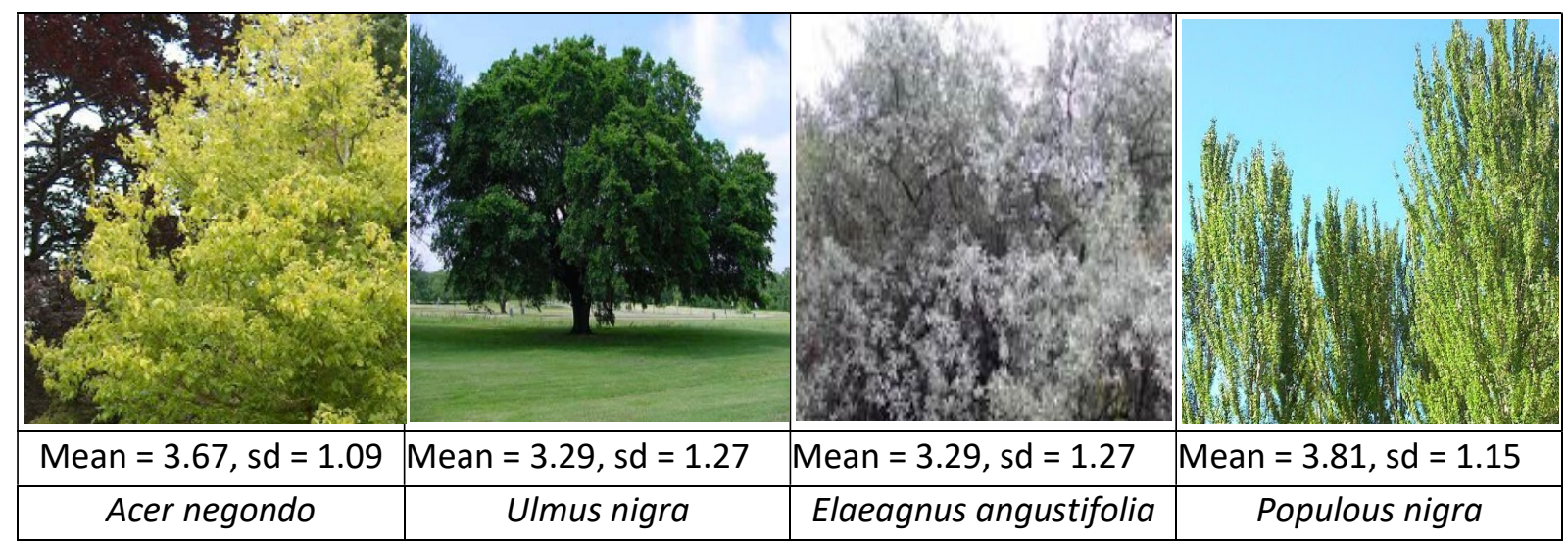

Figure 3a: Public Perceptions for Trees in Urban Park in Tabriz 


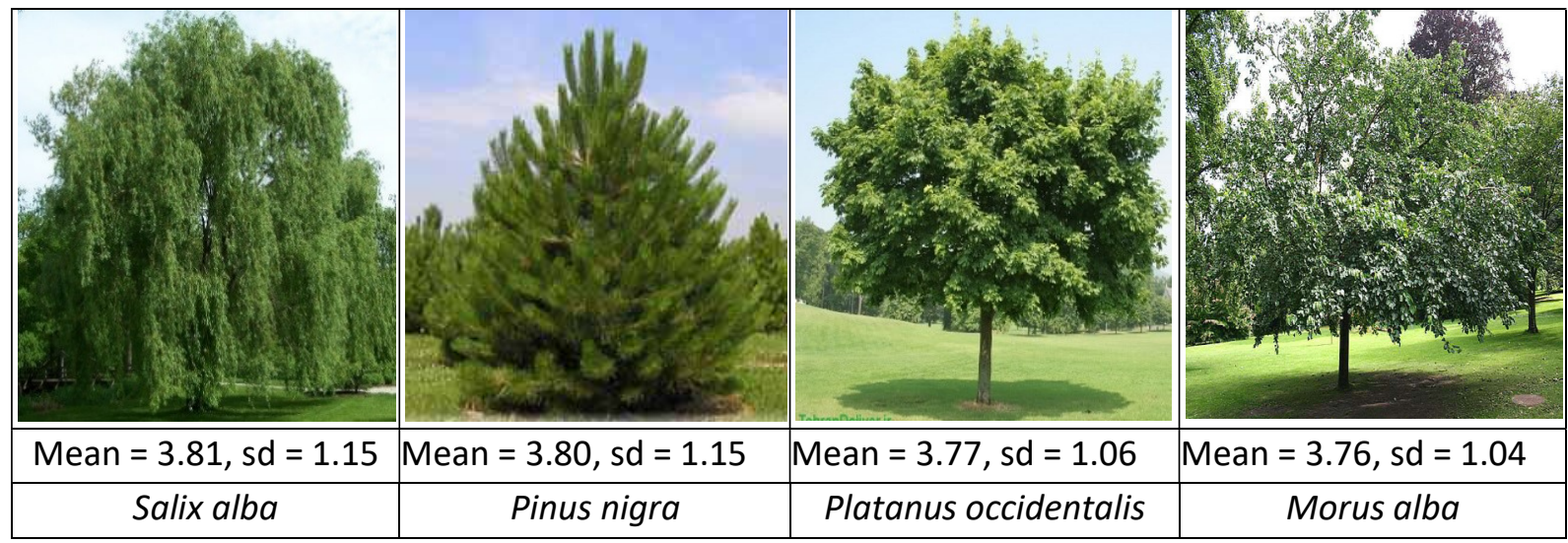

Figure 3b: Public Perceptions for Trees in Urban Parks in Tabriz

4.6 Mean Differences Results benweeen the Respondents' Demographic Variables into Landscape Preference Dimensions

Using independent sample t-test was in Table 5 revealed that females (mean $=4.23$ ) appreciate flowering plants more than males (mean $=4.00$ ) do, which is significantly different in $95 \%$ confidence $(t$ $=2.35, p=.035)$. There was no significant difference between gender groups into "presence of water" and "green enlargement" dimensions.

The results from one-way ANOVA shows a significant differences between people with "under diploma education (mean $=3.4$ )" and "above master education level" (mean $=4.30)$ towards "mental recovery" $(F=$ 3.54, $p=0.015$ ) dimension where the participants with higher education had the highest preferences. Table 6 also discloses significant difference between "evening visitors" (mean $=4.23$ )" and "afternoon visitors" (mean $=3.97$ ) towards preferences for "flowering purpose" ( $F=4.4, p=0.001)$. It means that evening visitors significantly have higher preferences than afternoon visitors for flowering landscape in parks.

The results of ANOVA in Table 7 reveals there is a significant mean differences between "those go to

Table 5: Mean Comparison between Gender Sub-group Using Independent Sample T-test ${ }^{1}$

\begin{tabular}{|l|c|c|c|c|}
\hline Dimensions & \multicolumn{2}{|c|}{ Gender groups } & T & P value \\
\hline & Male & Female & - & - \\
\hline Flowering Purpose & 4.00 & 4.23 & $2 / 35$ & .035 \\
\hline
\end{tabular}

${ }^{1}$ Cell entries are mean values based on 5 point Likert scale $(1=$ least preferred, $2=$ somewhat preferred, $3=$ neither preferred nor preferred, $4=$ preferred, $5=$ most preferred).

Table 6: Using One-way ANOVA for Education Level and Visitation Time into Preference Dimensions

\begin{tabular}{|c|c|c|c|c|c|c|}
\hline Dimensions & & Edu & tion level $^{1}$ & & $\mathbf{F}$ & P value $^{2}$ \\
\hline & $\begin{array}{c}\text { Under } \\
\text { diploma }\end{array}$ & Diploma & Bachelor & $\begin{array}{c}\text { Master and } \\
\text { above }\end{array}$ & - & - \\
\hline Mental recovery & $3.4^{\mathrm{a}}$ & $4.20^{b}$ & $4.37^{\mathrm{ab}}$ & $4.30^{b}$ & 3.54 & 0.015 \\
\hline & & Vis & tion time & & & \\
\hline & Night & Afternoon & Morning & Evening & $\mathbf{F}$ & $P$ value \\
\hline Green enlargement & 4.31 & 3.94 & - & - & 3.2 & 0.008 \\
\hline Flowering purpose & - & 3.97 & - & 4.23 & 4.4 & 0.001 \\
\hline Presence of water & - & 4.00 & - & 4.36 & 3.4 & 0.006 \\
\hline
\end{tabular}

\footnotetext{
2 the raw mean with different superscript differ significantly at $p<0.05$. 3Tukey was used for Post Hoc test)
} 
parks with wife" (mean $=4.02$ ) and "who visits the park with family" (mean $=4.44$ ) into the "presence of water" ( $F=4.2, p=0.006)$. Another interesting finding is that participants who come to the park more often have higher preferences (mean $=4.2$ ) to "presence of water" in the park, which is significantly different from another group ( $F=4.37, p=0.005)$.

\section{Discussion}

The participants prefer to sit under trees' shade and also observe moving water in urban parks. It has been stated that water has calming effects on humans (Nasar \& Lin, 2003). Based on the results, the visitors also have a high preference to look at flowers in the urban park landscape. Perhaps, the presence of flowers causes landscape diversity in parks and also enhance aesthetical pleasure of the place (Hami \& Tarashkar, 2018).

It was shown that education level has positive relation with preference for landscape benefits. It has been argued that as eduation goes up, the preference for moderate dense landscape increases (Bjerke et al., 2006). The results revealed that the majority of the respondents had university education level. The previous research has shown that greater education correlates with leisure activities (Hami, 2009).

Most of the participants prefer to visit the park with family members as well as with friends. Onlyfew participants visit the park alone. The results are similar to the previous findings that the majority of park visitors come to parks with family in Tabriz (Hami, 2009). This study supports findings of other researchers such as Sreetheran (2017) where he claimed that the majority of parks' visitors come to parks with group rather alone.

In the perspective of the participants, the landscape of urban parks offers people to engage with "aesthetically pleasing" and "relaxation and rest". The participants stated that people benefit from green spaces in urban parks in terms of "health care" and "mental recovery". Health care dimension consisting of mental activities such as contemplation, being in the natural environment, and relaxation. The previous research claimed that gardens with many native plants increase health benefits (Mitchell \& Popham, 2008). Another study claimed those who gain a lot of experience involving nature, can potentially receive greater wellbeing benefits (Shanahan et al., 2015). Overall, it can be said that natural settings are very much appropriate for mental activities.

Regarding the type of trees, the public users displayed the highest preference for Salix alba, followed by Pinus nigra, Platanus occidentalis, and Morus alba. Salix alba is one of the most popular and adopted species in Tabriz city. This species is very common for the residents in Tabriz and perhaps familiarity has caused higher preference as a recent research showed that women visitors prefer to see native trees more than exotic trees in the urban parks in Tabriz (Hami \& Tarashkar, 2018). In addition, Salix alba, Platanus occidentalis, and Morus alba are very suitable species to creating shade and cool area in parks compared to other plants, meanwhile, they do not emit any allergenic materials for anyone, which is a very common problem in urban parks nowadays. These plants have also medium dense canopy and rounded shape, which may also be cited as another effective attributions of trees. It is coincident with the previous research by Hami (2014a) where the scenes consisted of round shape trees with broadleaf were highly preferred compared to the scenes comprised of trees with needle leaves. He also reported that the landscape scenes with deciduous trees received higher preferences in compare with the scenes include evergreen trees. Another research, likewise, revealed that the trees shape, canopy, and shade are important factors in peoples' preferences for them (Lohr \& Pearson-Mims, 2006). Beside, the results of another study bared that people had high preferences ratings into moderately dense scenes in urban parks (Bjerke et al., 2006).

Even Pinus nigra received second top priority but it could not be suggested as an appropriate tree for urban park landscaping since it has dusty leaves. In addition, the canopy of Pinus nigra is very near 
to the ground and it does not let people benefit from its shades. Moreover, the plants with dense canopy will block the view, which leads to feelings of not being safe at the park as cited by Hami and his colleagues (2014b). It can be concluded that ecological needs are not only significant criteria of trees' selection, but functional attributions and aesthetical characteristics are important as well.

The study shows that as education of people goes up, the tendency for mental recovery demand in urban park landscape increases. As the prevous research has shown sociodemgraphic of park users correlate with preference for recreation in green spaces (Zhang et al., 2013). It is not quite surprising because people with higher education might have better and deeper knowledge about interaction of nature and men or maybe they also need it more because they are more stressed, which cause human well-being such as mental restoration. In a previous study, the researcher explained that neighbourhoods with a high density of trees showed positive association with physiological stress recovery (Jiang et al., 2014), social cohesion (Holtan et al., 2015), and fewer antidepressant prescriptions (Taylor et al., 2015). Also, Ulrich (1991) claimed that natural and urban environments have positive effect on reducing the physiological stress. Presence of water played a credible role in pulling people to visiting the urban park. In addition, water had meaningful influence on repetition of park visiting. Water was very important especially for the participants those who were accompanied by family members in the urban park. Landscape beauty and its esthetical values draw much attention from the participants. It is supported by Helfand et al., (2006) that if the landscapes satisfy peoples' views of attractiveness they will support them. Females liked flowers in significant different level from males, perhaps, because they have much atomistic perspective against holistic approach of males. The recent conducted study by Hami and Tarashkar (2018) has shown that flowers were highly preferred by women in urban parks. This study cannot verify and prove quality of women's approach towards landscape in urban, thus, an independent research herein can be useful and fruitful.

\section{Conclusions}

The study suggests that in designing landscape for urban parks, aesthetical purpose should be considered as a top priority in plant selection. People prefer to enjoy watching flowers and water in moving form. To enhance aesthetical values of park landscape, flowering plants should be considered in the plant selection of Iranian urban parks. In this aspect, cultivating of perennial flowers and flowering shrubs is highly recommended. It is proposed to plant more native trees in urban park landscape, which sustain longer and perhaps provide much preferred atmosphere in parks. Adding native plants to landscape designs seemed to have positive effects on homeowner preference for the landscaping (Peterson et al., 2012). The findings illustrate that an important attention should be given into familiarity of plants too. Using familiar plants in urban park might be considered as important factor in forming people preferences for landscapes.

Trees' attribution should be noticed another main criteria in planning of urban park landscape. Form, size of the leaf, leaf texture, canopy shape, and porosity can be known important characteristics of trees. These criteria influence the ability of trees to provide shade and thermal comfort. Therefore, it is essential that peoples' perception for native plants in residential areas to be taken as future research to discover the main reasons of differentiation in preferences, which will led to better landscape design in urban park. Deeper studies on ecological approach in selection of plants (form, canopy, texture, and porosity) for urban park need to be taken in future related landscape research.

\section{Acknowledgment}

The authors would like to acknowledge providing research equipments and facilities by University of Tabriz, Iran, and financial support particularly on the publication fee from the Research Management Centre (RMC), Universiti Putra Malaysia (UPM) 


\section{References}

Bjerke, T.; Østdahl, T.; Thrane, C. \& Strumse, E. 2006. Vegetation density of urban parks and perceived appropriateness for recreation. Urban Forestry \& Urban Greening, 5(1), 35-44. DOI: 10.1016/j. ufug.2006.01.006

Botzat, A.; Fischer, L. K. \& Kowarik, I. 2016. Unexploited opportunities in understanding liveable and biodiverse cities. A review on urban biodiversity perception and valuation. Global Environmental Change, 39, 220-233. DOI: 10.1016/j.gloenvcha.2016.04.008

Chen, B.; Adimo, O. A. \& Bao, Z. 2009. Assessment of aesthetic quality and multiple functions of urban green space from the users' perspective: The case of Hangzhou Flower Garden, China. Landscape and Urban Planning, 93(1), 76-82. DOI: 10.1016/j. landurbplan.2009.06.001

Council of Europe 2000. The European Landscape Convention. Strasbourg (Accessed November 2015).

Daniel, T. C. 2001. Whither Scenic Beauty? Visual landscape quality assessment in the 21st century. Landscape and Urban Planning, 54(1-4), 267-281. DOI: 10.1016/S0169-2046(01)00141-4

De Vaus, D. 2002. Social Survey (I). Saga Publications Ltd.

Dupont, F.; Antrop, M. \& Van Eetvelde, V. 2015. Does landscape related expertise influence the visual perception of landscape photographs? Implications for participatory landscape planning and management. Landscape and Urban Planning, 141, 68-77. DOI: 10.1016/j. landurbplan.2015.05.003
Hami, A. 2009. Users' preferences of usability of urban parks in Tabriz, Iran. Universiti Putra Malaysia, Kuala Lumpur, Malaysia. http://psasir.upm.edu. my/id/eprint/11962 /(Date: 24.08.2018)

Hami, A.; Suhardi, M; Manohar, M. \& Shahhosseini, H. 2011. Users' preferences of usability and sustainability of old urban park in Tabriz, Iran. Australian Journal of Basic and Applied Sciences, 5(11), 1899-1905. https://www.researchgate.net/ publication/288316799_Users\%27_preferences_ of_usability_and_sustainability_of_old_urban_ park_in_Tabriz_Iran (Date: 05.09.2018)

Hami, A.; Suhardi, M.; Manohar, M. \& Malekizadeh, M. 2014a. Natural elements spatial configuration and content usage in urban park. International Journal of Architectural Engineering \& Urban Planning, 1(24), 15-23. http://ijaup.iust.ac.ir/ article-1-170-fa.html (Date: 24.08.2018)

Hami, A.; Suhardi, M.; Manohar, M. \& Malekizadeh, M. 2014b. The relationship between landscape planting patterns and perceived safety in urban parks in Tabriz, Iran. African Journal of Environmental Science and Technology, 8(2), 107113. DOI: 10.5897/AJEST2013.1486

Hami, A.; Fazilah Fazle, M., Sayyah, Z. \& Emami, F. 2016. Factors affecting people preferences toward environment landscape, case study: shopping mall in Kuala Lumpur. Journal of Current Research in Science, 4(2), 216- 225. DOI: 10.5923/j.ijcem.20160504.03

Hami, A. \& Tarashkar, M. 2018. Assessment of women's familiarity perceptions and preferences in terms of plants origins in the urban parks of Tabriz, Iran. Urban Forestry \& Urban Greening, 32, 168-176. DOI : 10.1016/j.ufug.2018.04.002

Helfand, G. E.; Park, J. S.; Nassauer, J. I. \& Kosek, S. 2006. The economics of native plants in residential landscape designs. Landscape and Urban Planning, 78(3), 229-240. DOI: 10.1016/j. landurbplan.2005.08.001 
Holtan, M. T; Dieterlen, S. L. \& Sullivan, W. C. 2015. Social life under cover: tree canopy and social capital in Baltimore, Maryland. Environment and behavior, 47(5), 502-525. DOI: 10.1177/0013916513518064

Jiang, B.; Chang, C. Y. \& Sullivan, W. C. 2014. A dose of nature: Tree cover, stress reduction, and gender differences. Landscape and Urban Planning, 132, 26-36. DOI: 10.1016/j.landurbplan.2014.08.005

Kaplan, R. 1992. The psychological benefits of nearby nature. The role of horticulture in human well-being and social development. A national symposium (proceedings). Timber Press, Portland, OR, pp. 125-133.

Keniger, L.; Gaston, K.; Irvine, K. \& Fuller, R. 2013. What are the benefits of interacting with Nature? International Journal of Environmental Research and Public Health. 10, 913-935. DOI: 10.3390/ ijerph10030913

Kaźmierczak, A. 2013. The contribution of local parks to neighbourhood social ties. Landscape and Urban Planning, 109(1), 31-44. DOI: 10.1016/j. landurbplan.2012.05.007

Kirkpatrick, J. B.; Davison, A. \& Daniels, G. D. 2012. Resident attitudes towards trees influence the planting and removal of different types of trees in eastern Australian cities. Landscape and Urban Planning, 107(2), 147-158. DOI: 10.1016/j. landurbplan.2012.05.015

Lohr, V.I. \& Pearson-Mims, C.H. 2002. Childhood contact with nature influences adult attitudes and actions towards trees and gardening. IN: C.A. Shoemaker (ed.). International interaction by design: Bringing people and plants together for health and well-being, p. 267-277. lowa State Press, Ames, IA.
Lohr, V. \& Pearson-Mims, C. H. 2006. Responses to scenes with spreading, rounded and conical tree forms. Environment and Behavior, 38(5), 667688. DOI: 10.1177/0013916506287355

López-Martínez, F. 2017. Visual landscape preferences in Mediterranean areas and their socio-demographic influences. Ecological Engineering, 104, 205-215. DOI: 10.1016/j. ecoleng.2017.04.036

Maas, J.; Verheij, R. A.; de Vries, S.; Spreeuwenberg, P.; Schellevis, F. G. \& Groenewegen, P. P. 2009. Morbidity is related to a green living environment. Journal of Epidemiology \& Community Health, 63(12), 967-973. DOI: 10.1136/jech.2008.079038

Majnonian, H. 1996. Parks, Green Spaces, and Promenades. Tehran: Parks and Green Spaces Organization.

Mitchell, R. \& Popham, F. 2008. Effect of exposure to natural environment on health inequalities: An observational population study. The Lancet, 372(9650), 1655-1660. DOI: 10.1016/S01406736(08)61689-X

Mitra, A. \& Lankford, S. (1999). Research Methods in Park, Recreation, and Leisure Services. Illinois: Sagamore Publishing.

Muratet, A.; Pellegrini, P.; Dufour, A.B.; Arrif, T. \& Chiron, F. 2015. Perception and knowledge of plant diversity among urban park users. Landscape and Urban Planning, 137; 95-106. DOI: 10.1016/j.landurbplan.2015.01.003

Nasar, J. \& Lin, Y.-H. 2003. Evaluative Responses to Five Kinds of Water Features. Landscape Research, 28(4), 441-450. DOI: 10.1080/0142639032000150167 
Nilsson, K.; Sangster, M. \& Konijnendijk, C. C. 2011. Forests, trees and human health and well-being: Introduction. In Forests, trees and human health. Springer Netherlands. DOI: 10.1007/978-90-4819806-1_1

Oguz, D. 2000. User surveys of Ankara Urban Parks. Landscape and Urban Planning, 52, 165-171. DOI: 10.1016/S0169-2046(00)00130-4

Peterson, M.N.; Thurmond, B.; McHale, M.; Rodriguez, S.L.; Cook, M. \& Grove, J. M. 2012. Predicting native plant landscaping preferences in urban areas. Sustain Cities Social, 5, 70-76. DOI: $10.1016 / j . s c s .2012 .05 .007$

Rismanchian, O. 2009. The role of green space development in renewing a degenerating neighbourhood, a case study from Tehran, Iran. The 5th international conference of "CSAAR 2009: "Sustainable Architecture and Urban Development"; Libya. https://www.researchgate. net/publication/320923321 (Date: 25.08.2018)

Romianfar, S. Z. 2008. Tabriz urban parks. El Goli: Parks and Green Spaces Organization of Tabriz.

Rostami, R.; Lamit, H.; Khoshnava, S. M.; Rostami, R. \& Rosley, M. S. F. 2015. Sustainable cities and the contribution of historical urban green spaces: A case study of historical persian gardens. Sustainability, 7(10), 13290-13316. DOI: 10.3390/ su71013290

Shanahan, D. F.; Lin, B. B.; Gaston, K. J.; Bush, R. \& Fuller, R. A. 2015. What is the role of trees and remnant vegetation in attracting people to urban parks? Landscape Ecology, 30(1), 153-165. DOI: 10.1007/s10980-015-0162-z.

Sreetheran, M. 2017. Exploring the urban park use, preference and behaviours among the residents of Kuala Lumpur, Malaysia. Urban Forestry \& Urban Greening, 25, 85-93. DOI: 10.1016/j. ufug.2017.05.003
Suhardi, M. 2002. Seremban Urban Park, Malaysia: A Preference Study. Virginia Polytechnic Institute \& State University, Blackburg, Virginia. http:// hdl.handle.net/10919/33099 (Date: 25.08.2018)

Sullivan, W. C. 1994. Perceptions of the ruralurban fringe: citizen preferences for natural and developed settings. Landscape and Urban Planning, 29, 85-101. DOI: 10.1016/01692046(94)90020-5

Taylor, M. S.; Wheeler, B. W.; White, M. P.; Economou, T. \& Osborne N. J. 2015. Research note: Urban street tree density and antidepressant prescription rates-A cross-sectional study in London, UK. Landscape and Urban Planning, 136, 174-179. DOI: 10.1016/j.landurbplan.2014.12.005

Tuğrul Polat, A. \&Akay, A. 2015. Relationships between the visual preferences of urban recreation area users and various landscape design elements. Urban Forestry \& Urban Greening, 14(3): 573582. DOI: 10.1016/j.ufug.2015.05.009

Tveit, M. 2009. Indicators of visual scale as predictors of landscape preference; a comparison between groups.Journal of Environmental Management, 90(2), 2882-2888. DOI: 10.1016/j. jenvman.2007.12.021

Ulrich, R.S. 1991. Effects of Interior Design on Wellness: Theory and Recent Scientific Research. Journal of Healthcare Interior Design, 3, 97-109.

Van Dillen, S. M.; de Vries, S.; Groenewegen, P. P. \& Spreeuwenberg, P. 2012. Greenspace in urban neighborhoods and residents' health: adding quality to quantity. Journal Epidemiol Community Health, 66(6), e8-e8. DOI: 10.1136/ jech.2009.104695

Vouligny, E.; Domon, G. \& Ruiz, J. 2009. An assessment of ordinary landscapes by an expert and by its residents: Landscape values in areas of intensive agricultural use. Land Use Policy, 26, 890-900. DOI: 10.1016/j.landusepol.2008.10.016 
Wang, R. \& Zhao, J. 2017. Demographic groups' differences in visual preference for vegetated landscapes in urban green space. Sustainable Cities and Society, 28, 350-357. DOI: 10.1016/j. scs.2016.10.010

Zube E. H.; J.L. Sell \& Taylor, J.G. 1982. Landscape Perception: Research Application and Theory. Landscape planning, 9, 1-33. DOI: 10.1016/03043924(82)90009-0

Zhang, H.; Chen, B.; Sun, Z. \& Bao, Z. 2013. Landscape perception and recreation needs in urban green space in Fuyang, Hangzhou, China. Urban Forestry \& Urban Greening, 12 (1), 44-52. DOI: 10.1016/j. ufug.2012.11.001 